\title{
Mortality of Dutch coal miners in relation to pneumoconiosis, chronic obstructive pulmonary disease, and lung function
}

Jan M M Meijers, Gerard M H Swaen, Jos J M Slangen

\begin{abstract}
Objectives-To analyse the mortality patterns of former Dutch coal miners, focusing on coal workers' pneumoconiosis (CWP) and chronic obstructive pulmonary diseases (COPD) in relation to pre-existing impairment of lung function. Methods-3790 selected miners, medically examined between 1952 and 1963, were followed up to the end of 1991 with the municipal population registries and the causes of death from the death certificates were ascertained and converted to the codes from the ninth revision of the international classification of diseases (ICD9). Mortality comparisons were made with the male population in The Netherlands, resulting in standardised mortality ratios (SMRs). 3367 miners had radiological manifestation of CWP at medical examinations.
\end{abstract}

Results $-80 \%$ of the miners died during the follow up period. Excess mortalities from CWP (SMR 4523) and COPD (SMR 179) were found. Coal miners without CWP also showed an increased mortality from COPD (SMR 2913). A diminished lung function (forced expiratory volume in one second $\left(F E V_{1}\right)$, or $F E V_{1} / F V C$ (forced vital capacity) ratio) at medical examination resulted in a significantly increased SMR for COPD (322 and 212 respectively) whereas normal lung function yielded expected mortalities from COPD. A positive correlation also emerged between diminished lung function and the SMR due to CWP. The body mass index (BMI) at the moment of medical examination was correlated with the risk of dying of COPD and CWP: a decreasing BMI resulting in an increased SMR.

Conclusions-Not only infectious diseases and CWP but also COPD is an important cause of occupational mortality in miners with extensive exposure to coal mine dust. No obvious connection between preexisting CWP and the COPD mortality exists. Impaired $\mathrm{FEV}_{1}$ and FEV, /FVC ratios are predictors of an increased risk of COPD death. The BMI seems to indicate the severity of the COPD, resulting in premature death.

(Occup Environ Med 1997;54:708-713)
Keywords: coal miners; mortality; lung diseases

It is well known that coal miners are at an increased risk of developing pulmonary disease. Many longitudinal epidemiological studies in coal miners have been carried out in past years principally in Great Britain and the United States. Several studies have concentrated on the mortality due to respiratory diseases, cancer, and accidents in relation to the grade of coal workers' pneumoconiosis (CWP). Long term and high exposure to coal mine dust leads to premature death because of CWP. Furthermore, increased standardised mortality ratios (SMRs) have been found for respiratory tuberculosis, accidents, and stomach cancer. ${ }^{12}$

Most morbidity studies focused on the radiographic evidence of CWP in relation to exposure to dust. The long term cohort study in 26 collieries in Great Britain by the Institute of Occupational Medicine in Edinburgh produced comprehensive data on the clear doseresponse relation between exposure to coal dust and CWP. ${ }^{3}$

In recent studies attention has been given to the effect of exposure to coal dust on the decline of ventilatory capacity and obstructive airway disease (bronchitis, emphysema). These reports support an association between impairment in lung function, bronchitis, and exposure to dust as well as smoking. The National Institute for Occupational Safety and Health (NIOSH) longitudinal study in United States coal miners confirms that exposure to coal mine dust contributes significantly to a decline in forced expiratory volume in one second $\left(\mathrm{FEV}_{1}\right)$ over time. ${ }^{4}$ Exposure to coal dust causes reductions in $\mathrm{FEV}_{1}$, forced vital capacity (FVC), and the $\mathrm{FEV}_{1} / \mathrm{FVC}$ ratio. ${ }^{56} \mathrm{~A}$ recent large cohort study in United States coal miners confirmed the exposure-response relation between pulmonary function variables and the estimated cumulative exposure to dust. ${ }^{7}$

Several studies have pointed to the relation between exposure to coal mine dust and chronic obstructive pulmonary diseases (COPD). A study over a period of 22 years in 25000 British coal miners showed a consistent increase of mortality due to bronchitis and emphysema with increases in estimates of exposure to dust. ${ }^{8}$ Marine and Gurr ${ }^{6}$ clearly showed an increase in the prevalence of chronic bronchitis linked with increased exposure to dust for both smokers and non-smokers. Radiographic evidence of CWP does not influ- 
ence the prevalence of bronchitis. Kuempel et al found significant exposure-response relations for mortality from chronic bronchitis and emphysema after controlling for smoking. Ruckley et $a l^{10}$ concluded, after studying the lungs of 450 deceased coal miners, that the association between the exposure to coal dust and emphysema indicates a causal relation.

However, some debate about the increased risk of premature death because of COPD in miners exposed to coal dust and its relation to previous existing impairment in lung function and pneumoconiosis still exists. ${ }^{11}$

From 1902 until 1974 a coal mining industry existed in the southern part of The Netherlands, which in the late 1950s employed almost 20000 underground miners in 11 mines. ${ }^{12}$ All the mines were closed between 1965 and 1974.

Between 1952 and 1963 an extensive medical survey was carried out among 3790 coal miners with a long history of underground work and a high prevalence of CWP .

A retrospective cohort study was undertaken to analyse the time related mortality pattern in this group, focusing on CWP and COPD. Of special interest was the correlation between pre-existing impairment in lung function, as measured by the $\mathrm{FEV}_{1}, \mathrm{FEV}$, FVC, and FVC, and the mortality due to CWP and COPD.

\section{Materials and methods}

SELECTION OF STUDY POPULATION

Between 1952 and 1963 all miners in the 11 Dutch coal pits who were expected to retire within a few years, active miners, and retired miners with symptoms of airway diseases but without a compensation for occupational lung diseases were invited for an extensive medical examination through the Institute for Lung Diseases of the coal mines. One of the purposes of this medical examination was to evaluate whether or not a miner was eligible for a disability pension because of pneumoconiosis due to inhalation of coal mine dust. In total 3790 selected miners, all with a history of working underground, were systematically medically examined. The miners were of Dutch nationality and residence.

After closing down the Dutch coal mines the medical files of this selected group were kept by the Occupational Health Services of Dutch State Mines (DSM) and were made available for scientific purposes. The researchers computerised the existing personnel and medical information from these files.

\section{WORK HISTORY AND EXPOSURE ASSESSMENT}

A detailed working history for each minerincluding the mine in which he worked and the dates of starting and finishing underground labour-was recorded as part of the medical examination.

It was not possible to estimate the individual cumulative exposure to mine dust based on reliable, quantitative measurements for the coal miners in this retrospective study. The Dutch Technical Research Institute carried out limited dust measurements in 1963 in an unse- lected sample of 159 workplaces that represented the general exposure situation in the different coal pits. The daily mean total gravimetric dust concentration was $27.3 \mathrm{mg} /$ $\mathrm{m}^{3}$; the mean percentage of quartz was 5.33. Although relative differences in the dust concentrations between the pits and seams existed, underground exposure to mine dust has been generally high and was usually $>20$ $\mathrm{mg} / \mathrm{m}^{3}$. The working career of coal miners in the Netherlands was very similar: starting as a coal selector and moving to haulier, hewer and, possibly, supervisor.

Due to the lack of information about the exact workplaces-for example, histories and the use of protective dust masks as well as the limited number of dust measurements which showed an overall picture of high exposure to dust in Dutch mines - the total duration of underground employment was used as a surrogate measure of exposure.

Of the cohort $91 \%$ had worked more than 20 years underground at the moment of examination and the mean age of the miners in the survey was 51 years.

Dutch miners retired at the latest at 55. It was therefore decided to take the total years of underground employment until the medical examination as a measure of exposure. More stringent exposure differences were not introduced.

\section{MEDICAL SURVEY}

During the medical examination in the period 1952-63 a detailed questionnaire about diseases and complaints of the respiratory system (such as infections, bronchitis, asthma, emphysema, allergies, tuberculosis) was filled in for each miner by an occupational physician. Information about smoking was not systematically gathered. For 1458 miners (39\%) the current smoking status (non-smoker, cigarettes, pipes, cigars) was reported. Physical examinations included height, weight, heart action, and blood pressure.

In The Netherlands the radiological classification of pneumoconiosis differed from the corresponding 1950 International Labour Organisation (ILO) classification. Trained lung specialists in The Netherlands classified the disease as coal workers simple pneumoconiosis (CWSP) based on a lung radiograph showing irregular opacities, micronodulations, or nodulations with a diameter $\leqslant 10 \mathrm{~mm}$. The lung specialists classified the disease as progressive massive fibrosis (PMF) when coalescence into larger opacities (diameter $>10 \mathrm{~mm}$ ) and massive tumour tissue was present.

Spirometric measurements were obtained by trained personnel, with a wet spirometer. The $\mathrm{FEV}_{1}, \mathrm{FVC}$, and the $\mathrm{FEV}_{1} / \mathrm{FVC}$ ratio were analysed.

These values were expressed as a percentage of the reference value based on duration of service and age for men as proposed by the European Respiratory Society. ${ }^{13}$

DETERMINATION OF VITAL STATUS

The 3790 selected miners were followed up to 31 December 1991 with the municipal popula- 
Table 1 Vital status and cohort definitions of 3790 coal miners followed up to 31 December 1991

\begin{tabular}{lr}
\hline Alive (n) & 709 \\
Dead (n) & 2941 \\
Emigration (n) & 21 \\
Lost to follow up (n) & 119 \\
Total (n) & 3790 \\
Total person-years of follow up (n) & 77441 \\
Age of medical examination (mean (range)) & $51 \quad(20.2-82.7)$ \\
Duration of follow up (mean (range) & $20.5 \quad(1-39.8)$ \\
Underground working years (mean (range)) & $30 \quad(1-55)$ \\
\hline
\end{tabular}

tion registries in The Netherlands. Every inhabitant of The Netherlands must be registered at the population registry of the municipality in which he or she is living. In case of death, a certificate must be filed at the municipality in which the death occurred. The death certificate is always filed by a certified physician, in many cases the medical attendant. The death certificate is sent to the Central Bureau of Statistics, at which a trained nosologist codes the causes of death according to the latest international classification of diseases (ICD).

The Dutch annual vital statistics are generated from this database. In collaboration with the Central Bureau of Statistics, the causes of death for the cohort were ascertained. Taking into consideration the changes in ICD classifications that occurred during the period of follow up, the ICD codes were converted to the 9 th revision (ICD-9) ${ }^{14}$ and classified into broader categories.

Table 1 shows the results of the 1991 follow up for the coal miners. Of the cohort $3 \%$ was lost to follow up. Of the miners $80 \%$ had died during the follow up period. The mean duration of follow up was almost 21 years.

STATISTICAL ANALYSIS

The total and cause specific mortality experience of the cohort was examined from 1 January 1952 to 31 December 1991 . To correct for differences in age distribution, period of follow up, and fluctuations of background mortality, a person-time analysis was conducted by the computer program designed by
Peto. ${ }^{15}$ Comparisons of mortality were made with the total male population in The Netherlands. The cause, age, and five year period specific death rates of Dutch men were applied to the generated personal years of the coal miners' cohort to calculate expected numbers of deaths.

According to the indirect standardisation method, the SMR is the ratio of the observed number of cause specific deaths for each specific disease category and the expected number, multiplied by 100 . This is a measure of the relative risk of a specific cause of death in the study population of coal miners, in comparison with the mortality in the total male Dutch population, $95 \%$ confidence intervals (95\% CIs) were calculated as proposed by Breslow and Day. ${ }^{16}$

\section{Results}

Of the coal miners in the cohort, 423 had no radiological manifestations of CWP at the time of medical examination. Signs of CWSP were present in 2809 miners and 558 had PMF. The overall mortality between 1952 and 1992 was significantly increased (SMR 127.1, table 2). The highest mortality was found within 30 years after the examination, decreasing to an SMR of 114.8 in the period after 1980. The specific mortality due to infectious diseases and non-malignant respiratory diseases was responsible for the increased overall mortality. With the exception of the non-malignant respiratory diseases the increased mortality disappeared after 30 years of follow up. The SMR for tuberculosis was 1206.8, indicating that tuberculosis was an important and complicating disease in this group of coal miners. The significant excess mortality due to tuberculosis disappeared after 1970. The mortality due to pneumoconiosis, more specifically CWP, was very high during the total period of follow up (SMR 4523.2), and also sharply increased for each specific follow up period. As a result of CWP 323 miners had died in a period of 40 years, out of an initial population of $3367 \mathrm{~min}$ ers with CWP (9.6\%). The mortality due to

Table 2 Observed deaths (Obs) and SMRst by follow up period and cause, all coal miners, Netherlands comparison

\begin{tabular}{|c|c|c|c|c|c|c|c|c|}
\hline \multirow[b]{2}{*}{ Cause of death (ICD-9) } & \multicolumn{2}{|l|}{$1952-91$} & \multicolumn{2}{|l|}{$1952-69$} & \multicolumn{2}{|l|}{$1970-9$} & \multicolumn{2}{|l|}{$1980-91$} \\
\hline & Obs & $S M R$ & Obs & $S M R$ & Obs & $S M R$ & Obs & $S M R$ \\
\hline All causes of death & 2941 & $127.1^{\star}$ & 901 & $134.5^{\star}$ & 1076 & $133.8^{\star}$ & 964 & $114.8^{\star}$ \\
\hline Infectious, parasitic diseases (001-139) & 57 & $374.4^{\star}$ & 42 & $574.1^{\star}$ & 11 & $280.8^{\star}$ & 4 & 100.2 \\
\hline Tuberculosis $(010-018)$ & 37 & $1206.8^{\star}$ & 36 & $1531.9 \star$ & 1 & 193.8 & 0 & - \\
\hline All malignant neoplasms $(140-209)$ & 635 & 96.5 & 195 & 99.9 & 227 & 98.5 & 213 & 91.7 \\
\hline Benign neoplasms $(210-239)$ & 33 & 101.5 & 5 & 45.6 & 20 & $206.7^{\star}$ & 8 & 67.5 \\
\hline Diabetes mellitus (250) & 28 & 95.1 & 11 & 160.4 & 8 & 128.6 & 9 & 55.0 \\
\hline Circulatory diseases $(390-459)$ & 1152 & $108.5^{\star}$ & 330 & $114.9^{\star}$ & 421 & $111.2^{\star}$ & 401 & 101.3 \\
\hline Ischaemic heart diseases $(410-414)$ & 729 & $117.2^{\star}$ & 240 & $124.9^{\star}$ & 268 & $116.6^{\star}$ & 221 & 110.3 \\
\hline Non-malignant respiratory diseases $(460-519)$ & 761 & $411.0^{\star}$ & 240 & $539.9^{\star}$ & 285 & $453.2^{\star}$ & 236 & $303.2^{\star}$ \\
\hline Influenza and pneumonia $(460-487)$ & 45 & 76.9 & 17 & 109.7 & 18 & 104.2 & 10 & 38.9 \\
\hline COPD (490-496) & 186 & $179.2^{\star}$ & 48 & $310.9^{\star}$ & 73 & $177.9^{\star}$ & 65 & $137.3^{\star}$ \\
\hline Pneumoconiosis (500-508) & 323 & $4523.2^{\star}$ & 143 & $7359.8^{\star}$ & 24 & $1012.7^{\star}$ & 156 & $5514.3^{\star}$ \\
\hline Other respiratory diseases $(510-519)$ & 207 & $1317.4^{\star}$ & 32 & $276.7^{\star}$ & 170 & $7716.8^{\star}$ & 5 & $256.9^{\star}$ \\
\hline Non-malignant diseases of digestive organs $(520-579)$ & 59 & 82.4 & 16 & 68.1 & 22 & 101.9 & 21 & 79.2 \\
\hline Ulcer of stomach, duodenum (531-534) & 9 & 65.4 & 3 & 47.6 & 4 & 107.6 & 2 & 53.4 \\
\hline Cirrhosis of liver (571) & 17 & 122.7 & 5 & 99.3 & 7 & 143.4 & 5 & 126.9 \\
\hline Nephritis; nephosis (580-589) & 17 & 112.2 & 5 & 108.9 & 3 & 71.3 & 9 & 141.7 \\
\hline All external causes of death (800-999) & 71 & 87.4 & 26 & 73.9 & 33 & 128.5 & 12 & 59.0 \\
\hline Unknown (999.9) & 24 & & 2 & & 10 & & 12 & \\
\hline Person-years at risk & 77441 & & 41907 & & 22162 & & 13372 & \\
\hline
\end{tabular}

$\star \mathrm{P}<0.05$.

† SMR based on Netherlands expected deaths. 
Table 3 Observed deaths (Obs) and SMRT by deaths because of non-malignant respiratory diseases and duration of exposure (years), level of CWP, respiratory complaints, and smoking status

\begin{tabular}{|c|c|c|c|c|c|c|c|c|c|c|}
\hline & \multicolumn{10}{|c|}{ Cause of death (ICD-9) } \\
\hline & \multicolumn{2}{|c|}{$\begin{array}{l}\text { Total non-malignant } \\
\text { respiratory diseases } \\
(460-519)\end{array}$} & \multicolumn{2}{|c|}{$\begin{array}{l}\text { Influenza and } \\
\text { pneumonia }(460-487)\end{array}$} & \multicolumn{2}{|c|}{$C O P D(490-496)$} & \multicolumn{2}{|c|}{$\begin{array}{l}\text { Pneumoconiosis } \\
(500-508)\end{array}$} & \multicolumn{2}{|c|}{$\begin{array}{l}\text { Other respiratory } \\
\text { diseases }(510-519)\end{array}$} \\
\hline & $O b s$ & $S M R$ & Obs & $S M R$ & Obs & $S M R$ & Obs & $S M R$ & Obs & $S M R$ \\
\hline \multicolumn{11}{|c|}{ Duration of exposure (y): } \\
\hline$<20$ & 37 & $415.3^{\star}$ & 5 & 231.3 & 12 & $208.9^{\star}$ & 16 & $4324.3^{\star}$ & 4 & $631.9^{\star}$ \\
\hline$\geqslant 30$ & 458 & $366.7^{\star}$ & 31 & 73.5 & 108 & $161.9^{\star}$ & 184 & $3895.8^{\star}$ & 135 & $1195.7^{\star}$ \\
\hline \multicolumn{11}{|l|}{ Level of CWP: } \\
\hline No CWP & 74 & $357.1^{\star}$ & 10 & 138.5 & 37 & $2913.4^{\star}$ & 15 & $1973.7^{\star}$ & 12 & $626.6^{\star}$ \\
\hline CWSP & 517 & $368.5^{\star}$ & 28 & 63.8 & 120 & $150.5^{\star}$ & 223 & $4105.3^{\star}$ & 146 & $1253.6^{\star}$ \\
\hline PMF & 170 & $704.7^{\star}$ & 7 & 94.5 & 29 & $213.0^{\star}$ & 85 & $8966.2^{\star}$ & 49 & $2278.0^{\star}$ \\
\hline \multicolumn{11}{|c|}{ Respiratory complaints: } \\
\hline Yes & 240 & $502.9^{\star}$ & 14 & 92.5 & 77 & $290.2^{\star}$ & 85 & $4592.1^{\star}$ & 64 & $1520.6^{\star}$ \\
\hline No & 521 & $379.1^{\star}$ & 31 & 71.5 & 109 & $141.0^{\star}$ & 238 & $4499.1^{\star}$ & 143 & $1243.0^{\star}$ \\
\hline \multicolumn{11}{|l|}{ Smoking: } \\
\hline Smoker & 204 & $344.6^{\star}$ & 8 & 51.6 & 52 & $140.5^{\star}$ & 89 & $3705.2^{\star}$ & 55 & $1278.8^{\star}$ \\
\hline Unknown & 543 & $448.8^{\star}$ & 36 & 86.3 & 132 & 207.3 & 228 & $5025.3^{\star}$ & 147 & $1329.2^{\star}$ \\
\hline
\end{tabular}

$\star P<0.05$.

+ SMR based on Netherlands expected deaths.

COPD (186 deaths), especially chronic bronchitis and emphysema, was also significantly higher than expected (SMR 179.2). The increased SMRs for COPD occurred during the total follow up period. Mortality for the rest of the group of respiratory diseases was strongly increased. This group was probably polluted with many deaths from CWP and COPD.

Deaths due to circulatory diseases were significantly increased (SMR 108.5). This can be explained by the excess mortality from ischaemic heart diseases (SMR 117.2). After 30 years of follow up the increased SMR for cardiac diseases had levelled off.

There was no increased mortality for the group of malignant diseases and accidents in this group of coal miners.

In table 3 the mortalities from respiratory diseases are shown in relation to the exposure to coal mine dust, the level of CWP, and smoking. No unequivocal relation between the mortality from non-malignant respiratory diseases and the duration of exposure existed. Even after a period of exposure of $<20$ years, significant increases in mortality due to pneumoconiosis and COPD had already occurred. As the duration of exposure, and hence the cumulative exposure to coal dust, increased, there was no similar increase in SMRs for COPD and pneumoconiosis. Coal miners without any radiological signs of CWP at medical examination had a strongly increased risk of dying of COPD. If evidence of CWP was present at examination, the risk of dying because of COPD was still significantly increased, but much lower than in miners without CWP. This indicates a positive relation between exposure to coal mine dust and COPD, but no clear connection between CWP and mortality from COPD. Although the risk of dying from pneumoconiosis was increased in people without CWP at the moment of examination (SMR 1973.7), mortality from pneumoconiosis increased distinctively with the level of CWP. With an increasing level of CWP, the mortality from other respiratory diseases also increased.

Pre-existing respiratory complaints lead to an increased risk of dying from non-malignant respiratory diseases, especially from COPD (SMR with pre-existing complaints: 290.2; SMR without: $141.0 ; \chi^{2}=12.6, P<0.0001$ ), but not from acute infections and CWP. Smoking behaviour seems not to be clearly linked with the risk of dying from pneumoconiosis (SMR smokers 3705.2, SMR nonsmokers: 2970.3). It is evident that smokers

Table 4 Observed deaths (Obs) and SMR+ by deaths because of non-malignant respiratory diseases and the FEV, and FVC as percentage of the reference values and $F E V_{1} / F V C \times 100$

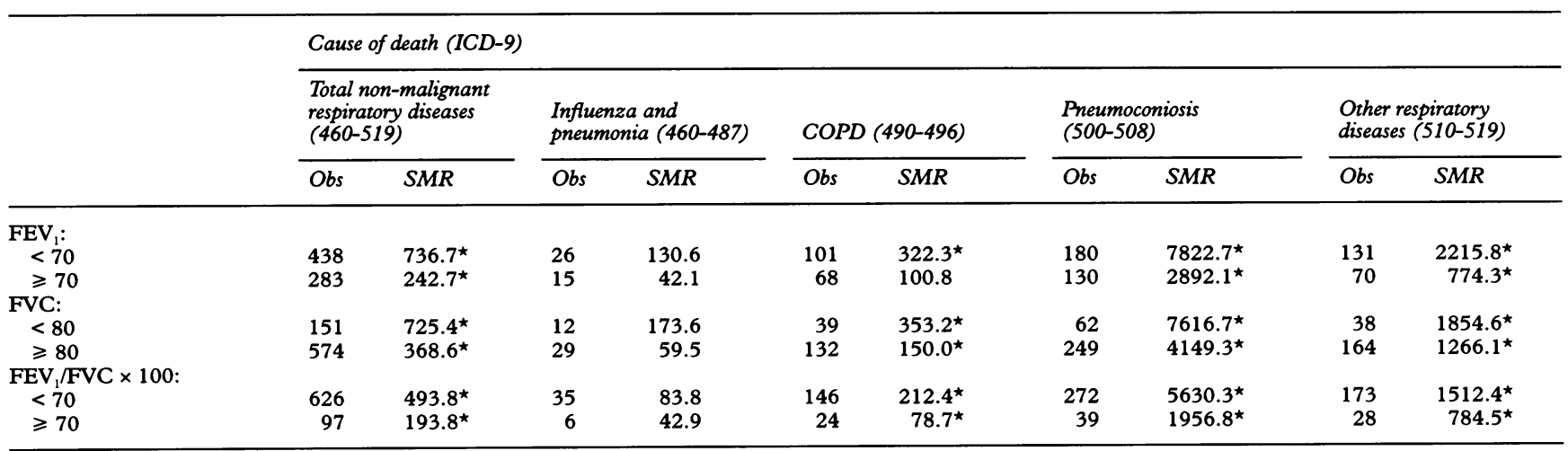

$\star \mathrm{P}<0.05$

+ SMR based on Netherlands expected deaths. 
have a significantly increased mortality risk from COPD (SMR 140.5).

Table 4 shows the SMRs for COPD and pneumoconiosis (CWP) in relation to the $\mathrm{FEV}_{1}, \mathrm{FVC}$, and $\mathrm{FEV}_{1} / \mathrm{FVC}$ ratio. A diminished $\mathrm{FEV}_{1}(<70 \%$ of expected) resulted in an increased SMR for pneumoconiosis (SMR 7822.7) and COPD (SMR 322.3). When the

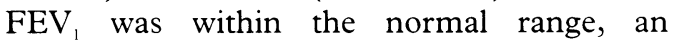
increased mortality for pneumoconiosis was still apparent, but the SMR for COPD was as expected. A decline in the FVC also showed increased SMRs for pneumoconiosis and COPD. The significantly increased SMRs remained for normal values of FVC, although the increases were much lower compared with diminished FVC. An $\mathrm{FEV}_{1} / \mathrm{FVC}$ ratio below the normal values resulted in increased SMRs for both pneumoconiosis (SMR 5630.3) and COPD (SMR 212.4), whereas normal FEV / FVC ratios led to an expected mortality from COPD (SMR 78.7).

The body mass index (BMI), defined as the quotient of weight (in $\mathrm{kg}$ ) and length ${ }^{2}$ (in $\mathrm{m}$ ), was related to the SMR for COPD and pneumoconiosis. A BMI $<20$ resulted in a significantly increased SMR of 424.1 for COPD. The SMR diminished with increasing weight, resulting in a still significantly increased SMR (215.7) for a BMI from 20 to 24 , and a non-significant mortality ratio with a $\mathrm{BMI}$ of $\geqslant 25$.

The SMR for pneumoconiosis was significantly increased for the total range of BMIs, with a trend of a decreasing SMR with an increasing BMI (BMI <20: SMR of 12790 ; $\mathrm{BMI} \geqslant 30$ : SMR of 2525).

\section{Discussion}

In the study population of coal miners presented there was an excess risk of mortality as a result of severe CWP, COPD, and tuberculosis. Almost $11 \%$ of the total mortality in the follow up period was due to CWP, and $6 \%$ due to COPD.

This cohort of coal miners clearly was no cross section of the total underground working population in Dutch coal mines, but a highly selected group of miners with a long occupational history and a high cumulative exposure to coal dust. Eighty nine per cent had CWP at the time of medical examination. The results of this study are not suitable to gain insight into the overall mortality characteristics of Dutch coal miners or to base exposure-response estimates on, but they provide evidence for an increased death rate from COPD in miners with a high cumulative exposure to coal dust, the relation with CWP, lung function characteristics, and body weight. Information about smoking has not been gathered systematically and a confounding effect through smoking cannot be entirely ruled out. However, $90 \%$ of the male Dutch population were smokers during the survey period. ${ }^{17}$ Because of this high prevalence a substantially higher percentage of smokers in this group of miners is not possible. Miners were not allowed to smoke during underground work. They had about 45 hours less each week to smoke than other workers. It is highly unlikely that the miners could consume more cigarettes every day than the average Dutch man. Because of these considerations smoking as a confounder cannot explain the excess mortality from CWP and COPD. Furthermore, should smoking as confounder influence the outcomes, we would expect the mortality from lung cancer in these miners to be higher than in the control population. This is surely not the case (SMR lung cancer 102).

It is interesting that coal miners without signs of CWP have a considerably increased risk of mortality from COPD. This could mean that a direct relation between COPD and CWP does not exist. These findings are in line with the outcomes of a study by Coggon et al, ${ }^{1 *}$ who indicate that the pathogenic mechanisms by which coal mine dust causes chronic bronchitis and emphysema depend on different features of the dust from those producing pneumoconiosis.

The results show that irrespective of a risk of CWP, there is a clear excess of risk of COPD in these miners, which is particularly present in the first 30 years after the end of exposure. Smoking and mortality due to CWP seem not to be clearly linked.

The mortality due to COPD is much higher in coal miners without CWP than in coal miners with CWP. We suppose that this can be explained partly by misclassification. If a person had both CWP and COPD, the physician who classified the death certificate will have been more inclined to classify the cause of death as CWP than COPD.

An impaired $\mathrm{FEV}_{1}$ and $\mathrm{FEV} / \mathrm{FVC}$ ratio are good predictors of an increased risk of dying from COPD. Thus it seems very important in occupational hygiene to prevent the occurrence of very severe obstructive airway diseases by withdrawing coal miners with an impaired $\mathrm{FEV}_{\text {, from work which generates a high }}$ amount of coal mine dust.

The risk of mortality from COPD in this group of miners is clearly correlated with the BMI. Lean miners have a higher risk of dying from COPD than people who are of normal weight or overweight. Low body weight is a complication of chronic bronchitis and emphysema, and influences the development of COPD negatively. ${ }^{1 "}$ Low body weight is the result of increased energy demand in these coal miners because of higher energy lost as a result of complicated respiration. The BMI seems to indicate the severity of the COPD, resulting in premature death.

The results of this study show that not only pneumoconiosis, but also COPD is a serious health and death risk for coal miners with a prolonged and high exposure to coal dust. It seems sensible to remove miners without signs of pneumoconiosis but with an impaired lung function and low BMI from work with a high exposure to coal dust.

We thank the Central Archives and Occupational Health Services of DSM for participating in the study and the Central Bureau of Statistics for providing the causes of death. 
1 Merchant JA. Coal workers' pneumoconiosis. In: RosenauLast M, Last JM, Wallace RB, eds. Public health and preventive medicine. New Jersey: Prentice-Hall, 1992.

2 Starzynski Z, Marek K, Kujawska A, Szymczak W. Mortality pattern in men with pneumoconiosis in Poland. Int $\mathcal{F}$ Occup Med Environ Health 1995;8:223-9.

3 Jacobson M, Rae S, Walton WH, Rogan JM. The relation between pneumoconiosis and dust exposure in British coal between pneumoconiosis and dust exposure in British coal
miners. Walton WH, ed. In: Inhaled particles III. Vol 2 . miners. Walton WH,

4 Attfield $\mathrm{MD}$. Longitudinal decline in $\mathrm{FEV}_{1}$ in United States coal miners. Thorax 1985;40:132-7.

5 Soutar CA, Hurley JF. Relation between dust exposure and lung function in miners and ex-miners. Brf Ind Med 1986; 43:307-20.

6 Marine WM, Gurr D. Clinically important respiratory effects of dust exposure and smoking in British coal miners. Am Rev Respir Dis 1988;137:106-12.

7 Attfield MD, Hodous TK. Pulmonary function of US coal miners related to dust exposure estimates. Am Rev Respir Dis 1992;145:605-9.

8 Miller BG, Jacobsen M. Dust exposure, pneumoconiosis, and mortality of coal miners. Br F Ind Med 1985;42:723-33.

9 Kuempel ED, Stayner LT, Attield MD, Buncher CR Kuempel ED, Stayner LT, Attfield MD, Buncher CR. Exposure-response analysis of mortality among coal m
in the United States. $\mathrm{Am} \mathcal{F}$ Ind $\mathrm{Med} 1995 ; 28: 167-84$.

10 Ruckley VA, Gauld SJ, Chapman JS, et al. Emphysema and dust exposure in a group of coal workers. Am Rev Respir Dis 1984;129:528-32.
11 Becklake MR. Chronic airflow limitation: its relationship to work in dusty occupations. Chest 1985;88:608-17.

12 Messing FAM. Geschiedenis van de mijnsluiting in Limburg. Leiden: Martinus Nijhoff, 1988.

13 Quanjer PhH, Tammeling GJ, Cotes JE, Pedersen OF, Peslin R, Yernault JC. Lung volumes and forced ventilatory flows. Report of the working party of the European Community for Steel and Coal on standardization of lung function tests. Official Statement of the European Respiratory Society. Eur Respir F 1993;6(suppl 16):5-40.

14 World Health Organisation. International classification of diseases, manual of the international statistical classificiation of diseases, injuries and causes of death. Geneva: WHO, 1977:1.

15 Peto J. Man-years: a program for computing observed and expected deaths or incidence rates. Oxford: ICRF Cancer Unit, 1980.

16 Breslow NE, Day NE. Statistical methods in cancer research. Vol II. The design and analysis of cohort studies., Lyon: IARC, 1987. (IARC Sci Publ No 82.)

17 Stichting Volksgezondheid en Roken. Den Haag: Jaarverslag, 1987:23.

18 Coggon D, Inskip H, Winter P, Pannett B. Contrasting geographical distribution of mortality from pneumoconiosis and chronic bronchitis and emphysema in British coal miners. Occup Environ Med 1995;52:554-5.

19 Muers MF, Green JH. Weight loss in chronic obstructive pulmonary disease. Eur Respir f 1993;6:729-34.

\section{Correspondence and editorials}

Occupational and Environmental Medicine welcomes correspondence relating to any of the material appearing in the journal. Results from preliminary or small scale studies may also be published in the correspondence column if this seems appropriate. Letters should be not more than 500 words in length and contain a minimum of references. Tables and figures should be kept to an absolute minimum.
Letters are accepted on the understanding that they be subject to editorial revision and shortening.

The journal also publishes editorials which are normally specially commissioned. The Editor welcomes suggestions regarding suitable topics; those wishing to submit an editorial, however, should do so only after discussion with the Editor. 